\title{
Hypervitaminia B12: A Useful Additional Biomarker for the Diagnosis and Monitoring of Liver Diseases
}

\author{
Abrar-Ahmad Zulfiqar ${ }^{1^{*}}$, Assia El Adli ${ }^{2}$, Jean Doucet ${ }^{1}$, Nadir Kadri ${ }^{1}$ and Emmanuel Andres ${ }^{3}$ \\ ${ }^{1}$ Department of Internal Medicine Geriatrics Therapeutics, University Hospital of Rouen, Rouen, France \\ ${ }^{2}$ Department of Emergency Unit, University Hospital of Reims, Reims, France \\ ${ }^{3}$ Department of Internal Medicine, University Hospital of Strasbourg, Strasbourg, France
}

"Corresponding author: Zulfiqar Abrar-Ahmad, Department of Internal Medicine Geriatrics Therapeutics, University Hospital of Rouen, Rouen, France, Tel: 0627102493; E-mail: abzulfiqar@gmail.com

Received date: Jul 01, 2016, Accepted date: Jul 18, 2016, Publication date: Jul 22, 2016

Copyright: ( 2016 Zulfiqar AA, et al. This is an open-access article distributed under the terms of the Creative Commons Attribution License, which permits unrestricted use, distribution, and reproduction in any medium, provided the original author and source are credited.

\begin{abstract}
$\mathrm{B}_{12}$ hypervitaminemia is a biological abnormality, yet one that is significantly underestimated. According to the literature, high levels of vitamin B12 is associated or linked with a range of conditions, the majority of which are serious. These conditions include solid neoplasia (whether metastatic or otherwise) and, either acute or chronic, malignant haematological disorders. But there are others causes like liver disorders, which are described in the literature, but poorly known.
\end{abstract}

Keywords: Hypervitaminia B12; Liver disorders; Hepatocellular carcinoma

\section{Introduction}

High serum levels of vitamin B12 or cobalamin, also called B12 hypervitaminemia, is a biological abnormality, yet one that is significantly underestimated. To date, no consensus on the management of this anomaly exists. According to the literature, high levels of vitamin B12 is associated or linked with a range of conditions, the majority of which are serious, with a systematic inquiry being decisive for prognosis following the discovery of high serum cobalamin level [1]. These conditions include solid neoplasia (whether metastatic or otherwise) and, either acute or chronic, malignant haematological disorders. But there are others causes like liver disorders, which are described in the literature, but poorly known. We illustrate this problematic in this clinical case.

\section{Case Report}

We received a 57-year old patient in our unit to treat a right cardiac decompensation. This is a patient with a medical history of chronic alcoholism complicated pathology of cirrhosis classified as Child Pugh C9, a non-anticoagulated atrial fibrillation, an alcoholic polyneuropathy, and benign prostatic hyperplasia. Clinically, the patient has NYHA class 2 dyspnea with the presence of peripheral edema of the lower limbs pitting. Pulmonary auscultation found crackles in the base of the lungs without any sign of respiratory severity; this leads to the initiation of hydro-sodium depletion. On the digestive side, the abdomen is bloated, without signs of venous collateral circulation, without any transit disorders; the hernial orifices are clear. We do not notice dullness, but there is a presence of conjunctival jaundice. Liver enlargement due to cirrhosis is hardly noticeable due to a bloated abdomen. The patient does not exhibit signs of encephalopathy, or flapping tremor. We have requested an abdominal ultrasound to look for eventual ascites, which may indicate edema-ascites decompensation. The hydro-sodium depletion enabled a regression of vascular overload signs.

The ultrasound confirms the presence of a dysmorphic liver. But this is associated to the presence of a nodule that is $2.7 \mathrm{~cm}$ in diameter in the right liver. It also reveals portal hypertension with inversion of the flux port. There were no ascites discovered and hepatic veins are permeable. On the biological side, a macrocytosis (MCV: $105 \mathrm{fl}$ ) without anemia is noted; prothrombin time is reduced to $50 \%$. Liver function tests only show a rise in total bilirubin to be $53 \mu \mathrm{mol} / \mathrm{l}$ (normal laboratory value: 2-18) without liver enzymes and without cholestasis. The albumin levels are $20.5 \mathrm{~g} / \mathrm{l}$ (normal laboratory value: 35-52). Note the presence of hypervitaminemia B12, with an estimated rate of $865 \mathrm{pg} / \mathrm{ml}$ (normal laboratory value: 191-485 pg/ml). The ACE rate is negative and we noted an increase in the rate of alphafetoprotein to $200 \mathrm{ng} / \mathrm{ml}$ (normal laboratory value: $<10 \mathrm{ng} / \mathrm{ml}$ )

As a result of this clinicobiological combination of the discovery of a liver nodule, high alpha-fetoprotein levels, and elevated serum vitamin B12 levels, there is suspicion of hepatic neoplasia. Thus, the liver MRI performed uncovered a $25 \mathrm{~mm}$ nodule in the lateral right sector of the liver, which is very likely pointing towards hepatocellular carcinoma. The thoracco-abdominopelvic CT scan confirms the hyper arterialized lesion of $25 \mathrm{~mm}$ with wash out on the right section on a dysmorphic liver suggesting hepatocellular carcinoma. A gastroenterological treatment is prepared.

\section{Discussion}

The link between B12 hypervitaminemia and solid neoplasia was demonstrated by Carmel et al. [2], when they studied vitamin B12 levels and vitamin B12 transporters in a population of 139 oncology patients [2]. The major cancers that were implicated were hepatocellular carcinoma (HCC) and secondary hepatic tumors, breast cancer, colon cancer, stomach cancer and pancreatic tumors [3]. Deneuville et al. [4] further defined the link between high serum levels of vitamin B12 and neoplasia with an OR of 1.8 across all cancers, 2.9 for metastatic tumors, 3.3 for HCC, 4.7 for other primitive hepatic 
Citation: Zulfiqar AA, El Adli A, Doucet J, Kadri N, Andres E (2016) Hypervitaminia B12: A Useful Additional Biomarker for the Diagnosis and Monitoring of Liver Diseases. J Blood Disord Transfus 7: 362. doi:10.4172/2155-9864.1000362

Page 2 of 2

tumors and 6.2 for neoplasia with hepatic metastasis. Fifty percent of hepatocellular carcinoma cases were linked to B12 hypervitaminemia, demonstrating a correlation with tumor size in certain cases [5]. The literature features reports of a link between B12 hypervitaminemia and acute or chronic liver disease [5]. These situations should be distinguished between acute liver disease, chronic liver disease, and hepatocellular carcinoma. In cases of acute liver disease, B12 hypervitaminemia is encountered in 25 to $40 \%$ of patients. Alcohol consumption may also be associated with elevated vitamin B12 levels, even in the absence of a manifest hepatic condition [1]. In the case of alcohol-induced hepatitis, a correlation has been reported between vitamin B12 levels of $>800 \mathrm{pg} / \mathrm{ml}$ in serum and both the severity of the liver disease and the mortality rate [6]. Dou et al. [7] identify vitamin B12 as a predictive factor for severity and mortality at three months in acute cases of chronic liver disease, particularly for levels $>1,200 \mathrm{pg} / \mathrm{ml}$ or even $2,000 \mathrm{pg} / \mathrm{ml}$. Multiple studies confirm the significant link between B12 hypervitaminemia and liver disease. In an internal medicine study, $31 \%$ of patients with elevated B12 had non-neoplastic liver disease, with $80 \%$ of cases being chronic and $25 \%$ having reached the stage of cirrhosis [8]. Similarly, the BDOSE study found that alcoholism (with or without manifest hepatic abnormalities) and neoplasia was the most frequent causes of B12 hypervitaminemia [8]. Deneuville et al. [4] identified a link with an odds ratio of 4.3. Zulfiqar et al. [9] confirmed this fact, factors with a significant link to hypervitaminemia $\mathrm{B} 12$ in univariate analysis were: acute renal failure $(p=0.0002)$; liver diseases $(p<0.0001)$ and solid neoplasia $(p=0.0030)$. Hepatic metastases were on the threshold of significance $(\mathrm{p}=0.0622)$, and variables independently related to hypervitaminemia B12 were: acute renal failure: (Odds Ratio $[\mathrm{OR}]=6.3 ; 95 \% \mathrm{CI}=2.7-8.1 ; \mathrm{p}<0.0001$ ); liver diseases $(\mathrm{OR}=5.4 ; 95 \% \mathrm{CI}=3.1-6.9 ; \mathrm{p}<0.0001)$; hematological disorders $(\mathrm{OR}=5.7 ; \mathrm{p}=0.0017)$; and age $\geq 75$ years $(\mathrm{OR}=3.7 ; 95 \%$ $\mathrm{CI}=1.9-4.8 ; \mathrm{p}=0.0416)$. The pathophysiologic mechanism is an excess cobalamin release by the liver and the hepatic synthesis decrease of Transcobalamin II, which is essential for tissue fixation of B12 vitamin [10].

\section{Conclusion}

Hypervitaminia B12 can be used as a useful biomarker in the diagnosis of malignant liver disease, and their prognosis.

\section{References}

1. Andrès E, Serraj K, Zhu J, Vermorken AJ (2013) The pathophysiology of elevated vitamin B12 in clinical practice. QJM 106: 505-515.

2. Carmel R (1975) Extreme elevation of serum transcobalamin I in patients with metastatic cancer. N Engl J Med 292: 282-284.

3. Serraj K, Mecili M, Housni I, Andrès E (2011) Hypervitaminemia B12 (high level of cobalamin): physiopathology, role and interest in clinical practice. Presse Med 40: 1120-1127.

4. Deneuville T, Mario N, Tiev KP, Tolédano C, Josselin-Mahr L, et al. (2009) Concentration plasmatique élevée de la vitamine B12: un indicateur des maladies hépatiques ou tumorales. Rev Médecine Interne 30: $\mathrm{S73.}$

5. Boisson F, Fremont S, Migeon C, Nodari F, Droesch S, et al. (1999) Human haptocorrin in hepatocellular carcinoma. Cancer Detect Prev 23: 89-96.

6. Baker H, Leevy CB, DeAngelis B, Frank O, Baker ER (1998) Cobalamin (vitamin B12) and holotranscobalamin changes in plasma and liver tissue in alcoholics with liver disease. J Am Coll Nutr 17: 235-238.

7. Dou J, Xu W, Ye B, Zhang Y, Mao W (2012) Serum vitamin B12 levels as indicators of disease severity and mortality of patients with acute-onchronic liver failure. Clin Chim Acta 413: 1809-1812.

8. Chiche L, Jean R, Romain F, Roux F, Thomas G, et al. (2008) Clinical implications of high cobalamin blood levels for internal medicine. Rev Med Interne 29: 187-194.

9. Zulfiqar AA, Sebaux A, Dramé M, Pennaforte JL, Novella JL, et al. (2015) Hypervitaminemia B12 in elderly patients: Frequency and nature of the associated or linked conditions. Preliminary results of a study in 190 patients. Eur J Intern Med 26: e63-64.

10. Ermens AA, Vlasveld LT, Lindemans J (2003) Significance of elevated cobalamin (vitamin B12) levels in blood. Clin Biochem 36: 585-590. 